\title{
NÍVEL DE LESÃO EM MEMBROS INFERIORES DE BAILARINOS CLÁSSICOS
}

\author{
LEVEL OF INJURY IN LOWER LIMBS OF CLASSICAL DANCERS
}

\author{
Felix William Medeiros Campos ${ }^{1}$ \\ Janaina Alvarenga Aragão \\ Edênia Raquel de Barros Moura ${ }^{3}$ \\ Luciano Silva Figueiredo ${ }^{4}$ \\ Vitória Martins Granja de Moura ${ }^{5}$ \\ Michael Junior de Oliveira Luz
}

RESUMO: A dança, na verdade, acompanha o homem desde sua aparição e em sua organização social. Foram diversas as formas pelas quais esta atividade se manifestava no homem, ele dançava como meio de comunicação, acasalamento, interação de grupos, relações etc. O presente trabalho teve por objetivo, conhecer lesões ósseas - articulares mais comuns em bailarinos de dança clássica, decorrentes da forma de execução, quantidade de treino diários, especificamente do movimento e da Fadiga corporal, e tem como hipótese inicial a repercussão que existe na saúde do bailarino decorrente

\footnotetext{
I Graduado em Educação Física pela Universidade Estadual do Piauí-UESPI (2019). E-mail: felix12397@hotmail.com.

2 Possui graduação em Enfermagem e Obstetrícia pela Fundação de Ensino Superior de Olinda - UNESF (1999), mestrado em Saúde Coletiva pela UNISINOS-Universidade do Vale do Rio dos Sinos (2010) e doutorado em Gerontologia Biomédica pela Pontifícia Universidade Católica do Rio Grande do Sul (PUCRS). Atualmente é Professora Adjunto da Universidade Estadual do Piauí, com experiência na área de Saúde Coletiva, e hoje desenvolve pesquisas no semiárido nordestino acerca de direitos humanos, acesso de saúde de adultos de meia idade e idosos remanescentes quilombolas, envelhecimento relacionados a Povos de Comunidades Tradicionais, e Segurança Alimentar e Nutricional.

${ }^{3}$ Especialista em Saúde Pública com Ênfase na Estratégia de Saúde da Família pelo Instituto de Educação Superior Raimundo Sá. Graduada em acharelado em nutrição pela Universidade Federal do Piauí (20II) e graduada em licenciatura plena em educação física pela Universidade Estadual do Piauí (2006). Professora TI 4oh do Curso de Educação Física na Universidade Estadual do Piauí, Campus Professor Barros Araújo. Membro do grupo de pesquisa cadastrado no $\mathrm{CNPq}$ intitulado "Dinâmicas socioambientais, cultura e desenvolvimento no semiárido", enquadrado na linha de pesquisa "Condição de vida e saúde, políticas públicas da meia idade e do idoso de comunidades quilombolas". Mestranda no Programa de Pós-Graduação em Formação de Professores e Práticas Interdisciplinares - PPGFPPI pela UPE, Campus Petrolina-PE.

${ }_{4}$ Possui graduação em ciências biológicas e médicas pela Universidade Federal Rural de Pernambuco e doutorado em Ciências pela Universidade Federal do Rio Grande do Sul. Atualmente é professor Adjunto (DE) da Universidade Estadual do Piauí e professor permanente junto ao Mestrado Profissionalizante em Ensino de Biologia (PROFBIO) e colaborador no Programa de Pós-Graduação em Desenvolvimento e Meio Ambiente (TROPEN) da Universidade Federal do Piauí. Atua principalmente com temas relacionados a Práticas e Conhecimentos de Comunidades Tradicionais, Conflitos Socioambientais,DireitosHumanos,Etnoecologia/Etnoconservação/Etnodesenvolvimento, políticas públicas, Multiculturalismo, Segurança Alimentar e Nutricional, Extrativismo.

5 Acadêmica de Medicina da Faculdade de Medicina de Olinda (FMO). Atua na área de extensão voltada a Ortopedia e Traumatologia.

${ }^{6}$ Possui graduação em Licenciatura Plena em Educação Física pela Universidade Estadual do Piauí (2020). Atualmente é Técnico em Enfermagem - Secretaria Municipal de Saúde de Fronteiras-PI.
} 
de uma temporada exaustiva de treinos de dança clássica. A pesquisa ocorreu no Ballet Releve no município de Picos Piauí, integrando 23 bailarinos de dança clássica. Os voluntários eram mistos sendo 4 meninos e 19 meninas, cujo foi estabelecido que a turma pratica 12 horas semanais de treino de dança, Ioo\% da turma teve ao longo da sua carreira acadêmica um tipo de lesão. Dentro os bailarinos avaliados, apenas $9 \%$ estão com sobrepeso e $91 \%$ com o IMC normal. Entre os bailarinos entre II e I5 anos, $43 \%$ calçaram a primeira sapatilha aos io anos. Conclui-se que o período extremo de treino de dança clássica, a má alimentação, o esforço repetitivo de exercícios, e as horas de pouco descanso para o dançarino levam a uma fadiga corporal e a lesões ósseas - articulares.

Palavras-Chaves: Dança Clássica, Lesão, Sapatilha de Ponta.

ABSTRACT: Dance, in fact, accompanies man since his appearance and in his social organization. There were several ways in which this activity was manifested in man, he danced as a means of communication, mating, group interaction, relationships, etc. The present work had as objective, to know bone lesions - articular most common in dancers of classical dance, resulting from the way of execution, amount of daily training, specifically movement and body fatigue, and its initial hypothesis is the repercussion that exists in the dancer's health due to an exhaustive season of classical dance training. The research took place at Ballet Releve in the municipality of Picos Piauí, integrating 23 classical dance dancers. The volunteers were mixed, with 4 boys and 19 girls, whose group established that the class practices 12 hours a week of dance training, 100\% of the class had a type of injury throughout their academic career. Among the dancers evaluated, only $9 \%$ are overweight and $91 \%$ have a normal BMI. Among dancers between II and 15 years old, $43 \%$ put on their first ballet shoes at io years old. It is concluded that the extreme period of classical dance training, poor diet, repetitive exercise effort, and the hours of little rest for the dancer lead to body fatigue and bone - joint injuries.

Keywords: Classical Dance, Injury, Pointed sneakers.

\section{INTRODUÇÃO}

Segundo Agostini (2010) o movimento humano é um processo de altíssima complexidade, que se caracteriza por variedades e qualidades inumeráveis e por uma versatilidade de respostas motoras devido às várias combinações neuromusculares possíveis a cada momento. $\mathrm{O}$ homem desde o início do seu processo de desenvolvimento no meio intrauterino utiliza o movimento para se comunicar, logo o movimento é inerente ao homem até o final de sua vida.

Caminada (1999) explica que, inserido na evolução da dança, o homem por si só já era artista, buscando, a partir da sua luta constante de sobrevivência, uma atividade imaterial, nascendo da dança uma necessidade de expressar emoção de forma particular, mesmo ainda sob a forma instintiva derivada dos animais, só o homem que a dança se fez arte, em função da sua própria consciência.

O Brasil tem uma diversidade cultural que se caracteriza como uma das expressões mais significativas, formando varias possibilidades de aprendizagem. As danças trazidas ao Brasil, através de diversos povos, como os gregos e africanos, são sempre mostradas nas mídias e sofrem inúmeras 
influências, transformando-se e multiplicando-se a todo tempo, a dança é vista como como uma atividade rítmica e expressiva e que faz parte do documento de arte que tange aos aspectos criativos e a sua concepção como linguagem artística (BRASIL, 1997).

Segundo Ossona (1988) a partir do século XV, na Europa, foram definidas as posições básicas do balé, todas anti-anatômicas e que podem gerar desalinhamentos das estruturas articulares. Sua prática ficava restrita à nobreza e estava fortemente incorporada ao currículo da educação formal de adolescentes e jovens (GARCIA, 2003).

Pode-se, assim, dizer que o ballet clássico foi criado a partir das danças da corte e, com interferências significativas, tornou-se uma arte teatral, pois o público já o assistia. O bailarino dança para uma plateia e consolida a arte do movimento do corpo. Sua linguagem do ballet clássico se subdivide em diferentes estilos, como clássico (abordavam os mitos, deuses e semideuses), romântico (suas visionárias paisagens de fadas, sílfides e delicadas donzelas) e neoclássico (com formas mais livres) (LIMA, 1995).

O balé clássico tem inerente à sua prática o desenvolvimento de exercícios bilaterais com equilíbrio simétrico produzindo eficiente potência muscular e coordenação que resulta em menos esforço e economia do uso do corpo, objetivos muito semelhantes aos que se observa na prática de outros esportes (GELABERT, 1986).

O ballet clássico tem, como exigência de quem o pratica, o desempenho de um atleta. Exigências que são impostas por horas de ensaios, por conta de coreografias e a apresentação de espetáculos durante todo o ano, momentos dos quais faz a parte fisiológica e suas aptidões serem tão importantes, tanto quanto o desenvolvimento de suas habilidades (FRAÇÃO et al., 1995).

GANTRUS e ASSUMPÇÃO (2002) relatam que a necessidade de vitórias e superresultados nos esportes de alta competitividade e as consequências do excesso de treinamentos e competições, condiç̃̃es indispensáveis para se atingir o ápice esportivo, refletem em número crescente de lesões do aparelho locomotor nos atletas de alto nível.

Em uma análise de registros médicos realizados com bailarinos na faixa etária de Io a 2I anos, foi observado o diagnóstico, local e tipo de lesão, sendo detectado que $76 \%$ das lesões ocorreram nos membros inferiores, dentre estas o entorse de tornozelo foi o mais comum, como também foi observado que o índice de lesões cresce de acordo com o aumento da idade, o que sugere a prevenção de lesões primárias em jovens bailarinos.( LEANDERSON,20II).

A pratica da dança clássica também requer continuidade, especificidade, individualidade, precisão, coordenação psicomotora elevada, flexibilidade, lateralidade, noção espacial, 
condicionamento físico e expressão corporal (SIMAS e MELO, 200o). Portanto, diante desse cenário o presente trabalho teve por objetivo, conhecer as lesões ósseas - articulares mais comuns em bailarinos de dança clássica, decorrentes da forma de execução, quantidade de treino diários, especificamente do movimento e da fadiga corporal.

\section{Método}

Pesquisa de estratégia quantitativa, descritiva, de caráter exploratório. A pesquisa ocorreu no Ballet Releve no município de Picos-Piauí, integrando 23 bailarinos de dança clássica. Os voluntários eram mistos, sendo 4 meninos e 19 meninas.

Conhecida como Capital do Mel, o município de Picos teve o início do povoamento a partir da construção da capela, em 1754 sob a invocação de Nossa Senhora da Conceição pelo sertanista Antônio Borges Leal Marinho. A economia da época acompanhava a característica do estado na atividade pecuária. O ponto que fomentou o desenvolvimento da região partiu da Fazenda Curralinho ou Retiro Curralinho, da família Borges Leal. Picos atraiu muitos comerciantes, e de 1950 em diante aconteceu pontos marcantes, como eletricidade e abastecimento de água (IBGE, 2019).

Segundo IBGE (Instituto Brasileiro de Geografia e Estatística) o município se estende por $534,7 \mathrm{~km}^{2}$ e conta com 78.002 habitantes no último censo. A densidade demográfica é de 137,3 habitantes por $\mathrm{km}^{2}$ no território do município. Situado a 202 metros de altitude, Picos tem as seguintes coordenadas geográficas: Latitude: $7^{\circ} 5^{\prime}$ 13" Sul, Longitude: $41^{\circ} 28^{\prime}$ 12" Oeste (IBGE, 2019).

O Ballet relevê reside no município de Picos e dispondo de um bom espaço físico $\left(300 \mathrm{~m}^{2}\right)$, amplo, com salas de aula reservadas e climatizadas $\left(87 \mathrm{~m}^{2}\right)$, piso adequado para dança, recepção com sala de espera para os pais, camarins masculino e feminino.

O Ballet Relevê hoje conta com turmas de baby class para crianças de até 6 anos de idade, preliminar I com crianças de 7 a Io anos de idade, preliminar 2 com crianças de Io a I2 anos de idade, avançado com maiores de 12 anos e o corpo de baile que são os bailarinos que representam o ballet em competições e apresentações. As aulas são de segunda a quinta-feira e cada turma tem 2 dias de aula sendo uma hora de aula totalizando 2 horas semanais. Já o corpo de baile tem aulas e ensaios de segunda a quinta-feira todos os dias, somando um total de io horas semanais de pratica da dança clássica.

A coleta de dados iniciou com uma explanação do projeto de pesquisa e a sua importância para a população bailarinistica. Os participantes e ou responsáveis foram informados sobre o objetivo da pesquisa. Onde todos os participantes maiores de 18 anos assinaram o termo de consentimento 
livre esclarecido (TCLE) e o Termo de Assentimento livre esclarecido (TALE) sendo assinado pelos responsáveis no caso de menores.

Os sujeitos foram distribuídos em dois grupos para a devida melhor adequar a coleta de dados junto aos bailarinos, evitando qualquer forma de comparação sendo que o objetivo é identificar e não comparar, sendo Gi participantes que iam sendo avaliados o peso e a altura e o G2 que ao mesmo tempo fossem respondendo os questionários, se são ou não capacitados a atuar de tal forma qualquer exercício físico dando enfoque a pratica da dança clássica e questionários sobre perguntas ao longo de sua carreira como bailarinos.

A primeira forma de avaliação foi a anamnese que foi feita com o questionário de prontidão para a Atividade Física (PAR-Q) (MORAIS, 2019) que verifica se a pessoa está apta ou não a prática qualquer atividade física a qual o objetivo é de identificar a necessidade de avaliação clínica e médica antes do início da atividade física. O questionário é a primeira coisa que deve ser feito antes da prática de qualquer atividade física principalmente quando for inserido de forma regular.

A segunda forma se deu através de uma avaliação antropométrica que é um método de investigação utilizado pelos profissionais de educação física para iniciação de qualquer atividade física, que geralmente vem logo após a anamnese. A avaliação antropométrica se baseia na medição das variações físicas e na composição corporal global, e os parâmetros mais utilizados para a avaliação antropométrica são as medidas primárias (utilizadas isoladamente), peso, estatura, dobras cutâneas e circunferências e as medidas secundárias (combinadas) com o Índice de Massa Corporal (IMC), peso ideal, somatória de dobras cutâneas, entre outros.

As circunferências informam a presença de gordura corporal e analisam os padrões de distribuição dessa gordura. As circunferências que podem ser mensuradas são: pescoço, tórax, cintura, abdômen, quadril, coxa, panturrilha, braço, antebraço e punho. A relação das circunferências da cintura e do quadril (C/Q) podem ser usadas para identificação do risco de doença cardiovascular. O IMC é obtido a partir do peso de um indivíduo dividido por sua estatura ao quadrado. O IMC juntamente com outras variáveis, como por exemplo, a circunferência da cintura, permite a identificação de risco de doenças cardiovasculares e analisam os padrões de distribuição da gordura corporal.

Esta avaliação considerou na tabela da Organização Mundial de Saúde (OMS.1997), logo após o IMC obtido foi feita uma comparação, onde o IMC menor que I8,5 indica um indivíduo magro e maior que 40,3 com obesidade grau 3 (mórbida), ainda existe suas subdivisões, são: de 18,6 a 24,9 IMC saudável, entre 25,0 e 29,0 a pessoa está com o peso normal, de 30,0 a 34,9 obesidade grau I e de 
35, o a 39,9 indica obesidade grau 2 (severa). Segundo a OMS, a medida de obesidade ou desnutrição é mais útil a nível populacional.

Como última forma de avaliação realizou-se com os bailarinos de dança clássica uma entrevista semiestruturada elaborada pelo próprio pesquisador, onde responderam perguntas sobre sua rotina semanal com horas, incluído hora de treino e hora de descanso, ao longo de sua carreira de bailarino profissional, se já teve alguma lesão e também perguntas como: idade, sexo, com quantos anos as meninas calçaram a sapatilha de ponta, se tem um acompanhamento do profissional de Educação Física e de outros da área da saúde de forma que permitisse ao estudo entender a relação bailarino e vida saudável.

Todo o processo de coleta de dados respeitou o limite dos bailarinos. Os critérios de exclusão foram através de pessoas que não pratica a dança clássica, bailarinas que não usam pontas.

A análise da coleta de dados foi feita de forma estatística, analisando um percentual total de bailarinos que apresentassem algum tipo de lesão, avaliando também o que os impediam de praticar esse tipo de atividade física, e assim, desenvolver a crítica da falta do profissional de Educação Física.

Os resultados demográficos e antropométricos, assim como o histórico de treinamento e histórico pessoal do bailarino, foram apresentados de forma descritiva analisados por meio de uma avaliação antropométrica e uma entrevista com o questionário de atividade de vida diária, elaborado pelo pesquisador. Como proposta para obtenção de informação de vida e carreira como bailarinos da sala de aula e preparo físico para competições.

\section{Resultados}

No gráficor são apresentados os IMCs dos bailarinos obtidos através da coleta das medidas antropométricas (peso e altura). Dentre os avaliados, $91 \%$ estão com o IMC normal e apenas 9\% se encontram com sobrepeso, isso ocorre devido ao alto nível de treino que proporciona aos bailarinos uma grande perca de gordura devido a atividade aeróbica e um ganho de massa magra deixando - o acima do peso, sendo que o IMC não determina a distribuição de gordura corporal. De acordo com Agostini (2010) devido ao alto nível de treino de dança clássica, a obtenção de resultados otimistas necessários no desenvolvimento de capacidades físicas visadas pelos bailarinos, é necessária uma persistência nos exercícios mesmo que mínima, com um intuito de propiciar uma duração que permita ocorrer as alterações bioquímicas e morfológicas necessárias. 
Gráfico I. Distribuição de IMC dos bailarinos, segundo a Idade, quantidade de treino semanal e classificação.

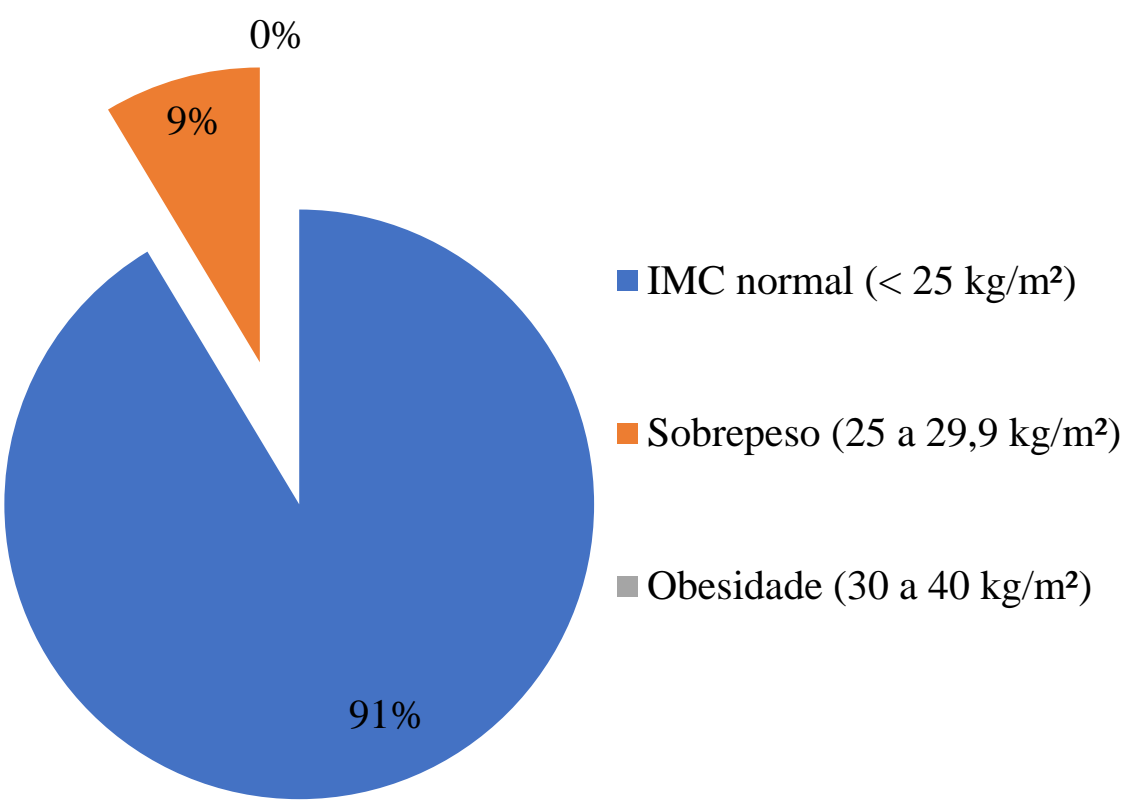

Fonte: (Dados da pesquisa, 2019).

Seguindo a classificação do gráfico I cujo $91 \%$ estão com o peso normal, a classificação geral foi dada através da tabela de IMC da Organização Mundial de Saúde (OMS.1997) cujo estabelece que entre 18,4 e 24,0 a pessoa está o peso normal e entre 25,0 e 29,o está acima do peso que são apresentados na pesquisa apenas em $9 \%$ dos entrevistados, nenhum apresentou obesidade ou abaixo do peso.

A pesquisa demonstrou uma associação significativa entre a idade e ano que calçou a primeira sapatilha. A maioria dos bailarinos da pesquisa tinham de II a I5 anos (43\%), entre 16 e 20 anos apenas $34 \%$ e mais de 2 I anos tinha 4,3\%, nota-se uma variabilidade de idade dos bailarinos. Porém, quando se fala de quando calçou a $\mathrm{I}^{\circ}$ sapatilha de ponta, I0o\% calçaram com Io anos de idade, tal como demonstra a tabela abaixo. 
Tabela I. Distribuição da predominância de idade das bailarinas e com quantos anos calçou sua primeira sapatilha de ponta.

\begin{tabular}{|c|c|}
\hline Variáveis & n (\%) \\
\hline \multicolumn{2}{|l|}{ Idade } \\
\hline o9 a io anos & (o) o\% \\
\hline II a Is anos & (го) $43,4 \%$ \\
\hline I6 a 20 anos & (o8) $34,7 \%$ \\
\hline 2I anos e mais & (oI) $4,3 \%$ \\
\hline \multicolumn{2}{|l|}{$\mathrm{I}^{\mathrm{a}}$ sapatilha de ponta (por idade) } \\
\hline o9 a ro anos & (23) $100 \%$ \\
\hline II a I5 anos & (o) o\% \\
\hline I6 a 20 anos & (o) o\% \\
\hline 2I anos e mais & (o) o\% \\
\hline
\end{tabular}

Fonte: (Dados da pesquisa, 2019).

$\mathrm{Na}$ da tabela $\mathrm{I}$, nota-se que independente da faixa etária todos os entrevistados quando calçaram a sapatilha tinham a idade entre o9 e ro anos (ıо\%). Segundo Dantas (1998) diz que os potenciais são determinados geneticamente, e as capacidades ou habilidades expressas são decorrentes do fenótipo, conclui-se que ao expor o bailarino ao início cedo do uso de sapatilha de ponta poderá desencadear - lhe lesões. Vaganova (199I) diz que há varias formas de sapatilhas de ponta, elas dependem da constituição do pé do bailarino. O mais confortável para dançar nas pontas é um pé cujos dedos sejam de tamanho igual com um pé baixo e sólido e um forte tornozelo.

Segundo Vaganova (199I), as bailarinas começam a dançar nas pontas entre Io a I2 anos o que colabora com os resultados dessa pesquisa, onde todos os bailarinos começaram a usar a sapatilha de ponta entre 9 e ro anos. $\mathrm{O}$ autor ainda ressalta que só o professor pode determinar a hora certa de colocar as pontas nos seus alunos, analisando todo o trabalho muscular realizando nas aulas, com o mínimo três aulas semanais.

Tabela 2: Distribuição dos bailarinos de acordo com sexo, carreira de bailarino clássico, nível de treino de acordo com a carga horária semanal, acompanhamento profissional de educação física, lesão (presença). 


\begin{tabular}{|c|c|}
\hline Variáveis & n (\%) \\
\hline \multicolumn{2}{|l|}{ Sexo } \\
\hline Feminino & $19(82,6 \%)$ \\
\hline Masculino & $04(17,3 \%)$ \\
\hline \multicolumn{2}{|l|}{ Carreira de bailarino clássico } \\
\hline or a 04 anos & $9(39,1 \%)$ \\
\hline o5 a io anos & $13(56,5 \%)$ \\
\hline II anos e mais & or $(4,3 \%)$ \\
\hline \multicolumn{2}{|l|}{ Nível de treinamento } \\
\hline \multicolumn{2}{|l|}{ (horas/semana) } \\
\hline or a o5 horas & (o) $0 \%$ \\
\hline o6 a io horas & (o) o\% \\
\hline II horas e mais & (23) $100 \%$ \\
\hline \multicolumn{2}{|l|}{ Acompanhamento profissional } \\
\hline Sim & \\
\hline Não & (o) o\% \\
\hline & (23) $100 \%$ \\
\hline \multicolumn{2}{|l|}{ Lesão (presença) } \\
\hline Sim & (23) $100 \%$ \\
\hline Não & (o) $0 \%$ \\
\hline
\end{tabular}

Fonte: (Dados da pesquisa, 2019).

A tabela 2 apresenta os entrevistados cujo 19 (82,6\%) são do sexo feminino e apenas 04 (17,3\%) são do sexo masculino, também percebeu - se que $56 \%$ tem mais de 5 anos de carreira de bailarino de dança clássica. Dos bailarinos entrevistados, todos (23) 100\% treinavam por II horas e mais por semana a dança clássica. Referente ao alto nível de treino, Sousa (2012) diz que é de fundamental importância que o profissional tenha uma base sólida da técnica do balé clássico, pois para o bailarino é imprescindível o conhecimento acerca de todo o processo da aula técnica. 
Detalha-se que de todos os entrevistados, nenhum tem um acompanhamento de um profissional de educação física, comparando que também todos apresentaram uma lesão a nível ósseo e articular ao longo de sua carreira, isso advém também da falta de acompanhamento desse profissional, cujo pode trabalhar junto ao bailarino. Sousa (2012) refere que o profissional de educação física também pode utilizar os métodos e inclui-los junto aos conteúdos da dança, inserindo todo o seu conhecimento anatômico e fisiológico.

De acordo com Gallahue (200I), o desenvolvimento motor está relacionado à idade, contudo não depende dele. Isso quer dizer que em uma sala de aula de dança clássica, pode ter alunas com a mesma idade, porém com aprendizados diferentes. Relacionando com a tabela 2, nota-se uma variável de idades entre os bailarinos, possível constatar que independentemente da idade a um mesmo nível de ganho no desenvolvimento motor. Logo a aprendizagem motora está relacionada ao desenvolvimento biológico, e experiências adquiridas no seu dia a dia.

\section{Discussão}

Este estudo teve por finalidade identificar qual a repercussão na saúde do bailarino em nível de lesão ósseo e articular, devido a um treino exaustivo de dança clássica. Verificou - se que esse risco de lesão nos bailarinos ocorre devido ao ritmo de treino, como também ao histórico de saúde dos bailarinos, que motivou a lesão devido ao uso da sapatilha de ponta tão cedo.

A presença de lesão total dos bailarinos mostrou-se que está associada ao uso de sapatilha de ponta, quando iniciado muito cedo na dança clássica, força a estrutura óssea muscular, os tendões e ligamentos, ocasionando a problemas ortopédicos graves na criança, como pé chato, no qual o mesmo não desenvolve a curvatura, deixando os ligamentos frouxos, criando hérnias da cápsula nos ligamentos das articulações ósseas e calosidades (ACHAR,1998).

Deformações imperceptíveis inicialmente podem se agravar, como problema de coluna, observados nas posturas quase sempre erradas. Várias são as bailarinas com joanetes, calos e com problemas no joelho. Podem surgir joelhos elásticos ou Poe trás, em consequência de ligamentos distendidos (MALANGA, 1985).

Alimentação deve ser um dos conteúdos da aula que o professor pode explorar, de forma lúdica e interativa, os nutrientes, as vitaminas e proteínas devem ser ensinadas, utilizando o balé como meio de chegar ao objetivo principal que é o conhecimento de uma boa alimentação. A duração dos exercícios depende do nível de estudo dos alunos, servindo como aquecimento dos diferentes grupos musculares. As aulas de ballet clássico acadêmico devem ser sistemáticas, os exercícios devem 
ser executados diariamente com duração mínima de 2 horas, é necessário que seja mantido este ritmo de aula para que o bailarino possa realizar um bom trabalho, principalmente em relação a técnica (SOUSA, 2012).

Os exercícios específicos de ballet são geralmente realizados com intensidade, duração e repetição elevadas, possibilitando a instalação de lesões (BOAS e GHIROTTO, 2006). Em suporte a tanto, os mecanismos de maior incidência de lesões físicas integram atividades de alongamento e saltos, exigências muito comuns no ballet (COSTA, FERREIRA e FELICIO, 2013).

Cabe ressaltar que a situação mais frequente que resultou em agravos entre as clássicas foi a execução de exercícios sobre a sapatilha de ponta que também exigem movimentos de flexão plantar. A elevada frequência de lesão pode também ser atribuída ao longo tempo que estas passam se exercitando sobre a sapatilha de ponta. Com o excesso de repetições a praticante passa a realizar os movimentos sem estabilidade adequada, tendo como agravante o fato de todo o peso corporal estar concentrado sobre os dedos (schon,1996).

A dança clássica trabalha essencialmente as amplitudes articulares do movimento, seus giros sobre ou fora do seu eixo corporal e o domínio do seu equilíbrio emocional, gera autoconfiança nos bailarinos que acaba ultrapassando os limites corporais, bem como a personalidade, conduz a autoestima e o amor próprio, que leva ao aprimoramento e o domínio da técnica (MALANGA, 1985).

Em uma pesquisa realizada com 358 estudantes de dança de quatro universidades americanas, das quais 164 responderam questionário sobre lesões relativas aos últimos cinco anos. Foram relatadas 229 lesões agudas, nas quais o joelho $46(20,1 \%)$ concentrou a maior proporção dos relatos (solomon,1986).

Um estudo feito para análise da sintomatologia dolorosa de bailarinos profissionais com uma amostra de I4I bailarinos, demostrou que dor é a maior queixa dos bailarinos e que está diretamente ligada às lesões sofridas por eles, sendo a região lombar a mais dolorosa, afetando 85,8\% da amostra, seguida por dores nos joelhos $(59,6 \%)$, na coluna cervical $(53,3 \%)$, quadril/coxa (direita $36,9 \%$ /esquerda $4 \mathrm{I}, 1 \%$ ) e pé (direito $40,4 \%$ / esquerdo $36,9 \%$ ), sendo que a maioria classificou a dor com intensidade de moderada a intensa( DORE,2007).

O ballet clássico, em quanto atividade desportiva, exige do praticante muitas habilidades e um treinamento que perpassa por um trabalho ósseo-mio-articular, na maioria das vezes, extenuante. $\mathrm{O}$ conhecimento do profissional de Educação Física especializados no ensino e no treinamento desta arte deve estar fundamentado em bases anátomo-cinesiológica que visem aperfeiçoar o desempenho de seus alunos-atletas de maneira segura, evitando o máximo o risco de danos que possam 
comprometer; tanto a pratica da atividade quanto o desenvolvimento normal dos indivíduos (AGOSTINI, 20I0).

Para tanto, a biomecânica e cinesiologia do balé retomam conceitos do alinhamento biomecânico fisiológico em que os pés devem suportar bem o peso do corpo, ficando em forma de um triangulo: um ponto no hálux, um ponto no quinto dedo e outro no calcanhar. $\mathrm{O}$ arco do pé deve ser estimulado para cima, evitando sobrecarga no hálux. Os pés são a superfície de maior contato com o solo, tanto antes de um impulso para realização de algum movimento tanto quanto na aterrissagem (ACHAR, 1998).

\section{Considerações finais}

Conclui-se que o período extremo de treino de dança clássica, a má alimentação, o esforço repetitivo de exercícios, e as horas de pouco descanso para o dançarino levam a uma fadiga corporal e a lesões ósseas - articulares. A exposição semanal também ao contrário de adquirir lesões, também causa um ganho bastante notável de capacidades físicas que vão influenciar no dia a dia dos bailarinos.

Quanto ao uso de sapatilha de ponta sendo aplicado aos bailarinos muito cedo, proporciona uma carreira profissional muito rápida, o ideal do bailarino profissional é começar muito cedo, mesmo quando criança, levando a uma serie de riscos a pessoa. O ritmo acelerando também é um grande causador de doenças, observando o tempo de treino de dança, comparando-se com as horas de sono e com quantas alimentações por dia, com certeza irá desenvolver na pessoa uma fadiga corporal muito grande podendo prejudicar no dia a dia da pessoa.

O profissional de Educação Física também é muito importante junto ao bailarino profissional, assim como outros profissionais da saúde, ajudando na vida diária, evitando prejuízos à saúde, caracterizando um trabalho em grupo, possibilitando a correção de exercícios, reflete-se que a falta de um profissional de educação física junto ao bailarino de dança clássica é prejudicial. Infelizmente nesse estudo os resultados mostraram um número muito relevante de bailarinos com lesão, o que pode está associada a falta de um acompanhamento do profissional de Educação Física.

Faz-se necessário não só o profissional de educação física junto ao bailarino, como também um nutricionista, um fisioterapeuta e até um psicólogo, para manter um aspecto físico e psicológico em ótimo estado sem prejuízo nenhum a saúde, a pesquisa apresentou bailarinos com lesões, com uma extremidade muito brande de tempo de treino de dança clássica, uma alimentação muito fraca e um tempo muito pequeno de descaço. Acredita-se que o ensino da dança clássica é de total 
importância para crianças quando cedo também, pois esse exercício físico é muito relevante para o desenvolvimento de capacidades físicas. Visto que na dança clássica existem movimentos básicos para ser humano como saltar, caminhar e até correr.

Devido ao crescimento da tecnologia a criança está deixando de brincar, para ficar dentro de casa sem fazer qualquer atividade física, e dança não vem só para o desenvolvimento do físico do ser humano, mais também para o desenvolvimento da socialização dos mesmos, ajudando a conviver em meio a sociedade. Já na adolescência a prática do ballet clássico mesmo com a presença de lesões, nota-se que é benéfica no que se refere ao exercício físico propriamente dito e estímulo ao crescimento, porém, é importante ter extrema cautela nas instruções, e focar na prevenção de lesões osteoarticulares, bem como, em transtornos alimentares intercorrentes.

A aplicação deste estudo no município de Picos foi de grande relevância, para explorar os riscos que a dança clássica tem para o desenvolvimento do ser humano, para salientar a forma correta de desenvolver esse tipo de atividade física, para orientar a importância da presença de um profissional de educação física presente na sala de aula, e também na detecção de possíveis doenças tornando possível o encaminhamento quando necessário ao médico para terem os devidos cuidados. Esse estudo também possibilita que outras pessoas possam ser orientadas antes mesmo de começar essa atividade física, a dança do ballet clássico.

\section{Referências}

ACHAR D. ballet: uma arte. Rio de janeiro: Ediouro, 1998.

AGOSTINI, Barbara Raquel: ballet clássico: preparação física, aspectos cinesiológicos, metodologia e desenvolvimento motor. red.Várzea Paulista, SP: Fontoura, 2010.

BOAS JÁ, GHIROTTO FM. Aspectos epidemiológicos das lesões em bailarinas clássicas. Ver Bras Cienc Saúde. V.2, n.7, p.447- 488, 2006.

BRASIL, Secretaria de Educação Fundamental. Parâmetros curriculares nacionais: introdução aos parâmetros curriculares nacionais/ secretaria de educação fundamental. Brasília: MEC/SEE, 1997

CAMINADA, E. História da dança: evolução cultural. Rio de janeiro: Sprint; 1999.

COSTA MS, FERREIRA AS, FELICIO LR. Equilíbrio estático e dinâmico em bailarinos: revisão de literatura. Fisio pesq. V.20, n.3, p.292- 298, 2013. 
DANTAS, E. H. M. A prática da preparação física. Rio de janeiro: shape, 1998.

Dore BF, Guerra RO. Sintomatologia dolorosa e fatores associados em bailarinos profissionais. Rev Bras Med Esporte. 2007;13(2):77-80.

FRAÇÃO V. VAZ MA. RAGASSON CA. MULLER IP. Efeito de treinamento na aptidão física da bailarina clássica. Ver Mov. V.5, n.II, p.13-15, 1995.

GALLAHUE, David L. compreendendo o desenvolvimento motor: bebes, crianças, adolescentes e adultos. São Paulo, SP: Phorte, 20or.

Gantus M. C.; Assumpção J. D. Epidemiologia das lesões do sistema locomotor em atletas de basquetebol. Revista Acta Fisiátrica. 2002;9(2):77-84.

Garcia A, Haas AN. Ritmo e dança. Canoas: ULBRA; 2003.

Gelabert R. Dancer's spinal syndromes. J Orthop Sports Phys Ther 1986; 7(4):180-9I.

IBGE - INSTITUTO BRASILEIRO DE GEOGRAFIA E ESTATÍSTICA. Disponível em: https://cidades.ibge.gov.br/brasil/pi/picos/panorama.acesso em: I9 mar. 2019.

Leanderson C, Leanderson J, Wykman A, Strender LE, Johansson SR, Sundquist K. Musculoskeletal injuries in young ballet dancers. Knee Surg Sports Traumatol Arthrosc. 20II; 19(09):1531-I535.

LIMA L. Dança como atividade básica: perspectiva parauma nova era. Rev. Brasileira medicina esporte, v.3, p.94- 96, 1995 .

MALANGA E. B. Comunicação e balé. São Paulo: EDIMA, 1985.

MEEREIS, E. C.W., et al. Sintomatologia dolorosa em bailarinos: uma revisão. R. bras. Ci. E Mov., v, 2I, n. 2, p. 143-150, mar-jan., 2013.

OMS- ORGANIZAÇÃO MUNDIAL DE SAÚDE. Disponível em: http://www.saude.gov.br/component/content/article/804-imc/40509-imc-em-adultos. Acesso em: I9 mar. 2019.

Ossona P. A educação pela dança. $2^{2}$ ed. São Paulo: Summus; 1988.

RABELO, T. M. Lesões nos membros inferiores em bailarinos clássicos: uma revisão de literatura. 2012. 34 f. Monografia - Universidade Federal de Minas Gerais, Belo Horizonte, 2012.

Schon LC, Weinfeld SB. Lower extremity musculoskeletal problems in dancers. Curr Opin Rheumatol 1996;8(2):130-42. 
SIMAS JP. MELO SI. Padrão postural de bailarinas clássicas. Ver Ed FIS UEM. V.II, p. 51- 57, 2000.

Solomon R, Micheli L. Concepts in the prevention of dance injuries: a survey and analysis. In: Broekhoff J, Ellis MJ, Tripps DG. The dancer as athtets. Champaign: Human kinetics Book; 1986.

SOUSA, Ana Aparecida Almeida de. A prática pedagógica do balé clássico na educação infantil: revelando caminhos. Várzea Paulista, SP: Fontoura, 2012.

VAGANOVA, A. princípios básicos do ballet clássico. Rio de janeiro: Ediouro, I99I. 